\title{
Antibacterial activities of plant essential oils against Legionella pneumophila
}

\author{
Ching-Wen Chang ${ }^{a, *}$, Wei-Lung Chang ${ }^{a}$, Shang-Tzen Chang ${ }^{b}$, Sen-Sung Cheng ${ }^{b}$ \\ anstitute of Environmental Health, College of Public Health, National Taiwan University, Taipei 100, Taiwan, Republic of China \\ ${ }^{\mathrm{b}}$ School of Forestry and Resource Conservation, National Taiwan University, Taipei 106, Taiwan, Republic of China
}

\section{A R T I C L E I N F O}

Article history:

Received 26 October 2006

Received in revised form

14 June 2007

Accepted 11 July 2007

Available online 14 July 2007

Keywords:

Legionella pneumophila

Essential oil

Antibacterial activity

Cinnamomum osmophloeum

Cinnamaldehyde

\begin{abstract}
A B S T R A C T
The objective of this study was to determine the antimicrobial activity of essential oils (EOs) extracted from Cinnamomum osmophloeum leaves and different tissues of Cryptomeria japonica against pathogenic Legionella pneumophila at $42{ }^{\circ} \mathrm{C}$. Ten kinds of EOs were extracted by water distillation and their chemical constituents were quantified by gas chromatography-mass spectroscopy (GC-MS). The results showed that cinnamon leaf EO possessed stronger anti-L. pneumophila activity than C. japonica EO. In particular, the highest bactericidal effect was noted in contact with C. osmophloeum leaf EO of cinnamaldehyde type (characterized by its major constituent of cinnamaldehyde accounting for $91.3 \%$ of EO), regardless of contacted cell concentration ( 2 and $4 \log \mathrm{CFU} \mathrm{m} l^{-1}$ ) or exposure time (10 and $60 \mathrm{~min}$ ). Cinnamaldehyde is responsible for anti-L. pneumophila activity based on the results of antimicrobial testing and statistical analysis. Stepwise regression analyses show that EO concentration is the most significant factor affecting the bioactivity of EO. It is concluded that $C$. osmophloeum leaf oil of cinnamaldehyde type and its major constituent, cinnamaldehyde, possess strong anti-L. pneumophila activities, and have the great potential to be used as an antibacterial agent to control legionellosis associated with hot tubs and spa facilities widely used in homes and resorts.
\end{abstract}

(c) 2007 Elsevier Ltd. All rights reserved.

\section{Introduction}

Legionella pneumophila is the pathogen responsible for severe pneumonia known as Legionnaires' disease (LD) and nonpneumonic Pontiac fever, collectively referred to as legionellosis (Fields, 1997). In addition to rivers and lakes (Fliermans et al., 1981), this bacterium may grow in hot spring water (Furuhata et al., 2004) and hot water outlets of hospitals, hotels and private apartments (Leoni et al., 2005). Contamination of L. pneumophila in hot tubs and spa facilities used in homes, resorts and exhibition shows has been associated with severe LD outbreaks (Den Boer et al., 2002; NIID, 2003) and many sporadic cases of legionellosis (Johnson et al., 1994; Miller et al., 1993; Thomas et al., 1993; Tolentino et al., 1996;
Watson et al., 2004), and even caused human deaths (Johnson et al., 1994). This indicates that use of spas and hot tubs presents a potential risk of legionellae exposure and may contribute to severe health effects (Den Boer et al., 2002; Johnson et al., 1994; NIID, 2003). It is estimated that approximately 5 million public and private hot tubs, spas and whirlpools are used in the United States (CDC, 2004).

With increasing awareness of legionellosis associated with spas and bathtubs, regular clean-up and disinfection of these becomes essential. In addition to superheating and chlorine disinfections, antimicrobial agents extracted from a variety of plants have recently been evaluated for their antibacterial properties against Legionella (Friis-Moller et al., 2002; Furuhata et al., 2003; Morita et al., 2004a,b). The application of plant

\footnotetext{
*Corresponding author. Room 740, 7F, No. 17, Xuzhou Road, Taipei 100, Taiwan, Republic of China. Tel.: +886233228104; fax: +886223516974.

E-mail address: chingwenchang@ntu.edu.tw (C.-W. Chang).
}

0043-1354/\$ - see front matter ๔ 2007 Elsevier Ltd. All rights reserved.

doi:10.1016/j.watres.2007.07.008 
extracts as a bactericidal agent in hot springs and public baths was suggested (Furuhata et al., 2003). Addition of plant extracts in bathtubs and spas may avoid the problems of accident scald and trihalomethane exposure concerned with superheating and chlorination, respectively. Besides, it is suitable for the prevention of legionellosis in resorts and independent residences without centralized water heating systems. However, up to now, there is only one type of plant extract (grapefruit seed extract) that has been tested on Legionella under warm water situation (Furuhata et al., 2003).

A variety of essential oils (EOs), the natural mixtures of volatile metabolites extracted from plants, show their biocidal effects on bacteria, fungi, viruses, protozoa, insects and plants (Kalemba and Kunicka 2003). Cinnamomum osmophloeum Kaneh. (Lauraceae) is an endemic tree in the natural hardwood forests of Taiwan at elevations between 400 and $1500 \mathrm{~m}$. The Japanese cedar, Cryptomeria japonica D. Don, on the other hand, is an important plantation tree of Taiwan with high values as a building material. The EO extracted from $C$. osmophloeum and $C$. japonica demonstrates inhibitory effect against bacteria (Chang et al., 2001), fungi (Morita et al., 1997; Wang et al., 2005) and other organisms such as mites (Chen et al., 2002). In particular, C. osmophloeum leaf EO was reported to inhibit the growth of Escherichia coli, Pseudomonas aeruginosa, Enterococcus faecalis, Staphylococcus aureus, Staphylococcus epidermidis, methicillin-resistant Staphylococcus aureus, Klebsiella pneumoniae, Salmonella sp. and Vibrio parahemolyticus (Chang et al., 2001). However, there are no reports regarding the antibacterial activity of $C$. osmophloeum and $C$. japonica EO against L. pneumophila. In light of the existence of Legionella exposure in hot tubs and of the antimicrobial activity of EO, it is interesting to study the bioactivity of various EOs obtained from C. osmophloeum and C. japonica on L. pneumophila. In this study, six EOs from C. osmophloeum leaves containing various chemical polymorphisms and four EOs from different tissues of $C$. japonica were extracted by water distillation. The chemical constituents and contents of extracted EOs were analyzed by gas chromatography-mass spectrometry (GC-MS). The antibacterial activity of EOs and one of the major chemical components, cinnamaldehyde, was further investigated against L. pneumophila at $42{ }^{\circ} \mathrm{C}$ for a contact period of $10-60 \mathrm{~min}$. This test water temperature represents the averaged hot bathing temperature (Bornstein et al., 1989) at which L. pneumophila has been isolated from the bath water during a LD investigation (Mashiba et al., 1993).

\section{Materials and methods}

\subsection{Bacterial strains and media}

L. pneumophila serogroup 1 ATCC 33152 was inoculated into buffered charcoal yeast extract agar supplemented with $\alpha$-ketoglutarate (BCYE $\alpha$ agar) (Sigma Chemical Co., St. Louis, $\mathrm{MO}, \mathrm{USA})$, and incubated at $37^{\circ} \mathrm{C}$ in an atmosphere of $5 \% \mathrm{CO}_{2}$ (Chang et al., 2007; Greub and Raoult, 2003) for 2 days. Forming colonies were removed and serial dilutions with sterile ultrapure water (Milli-Q Gradient, Millipore, Billerica, MA, USA) were performed to obtain a concentration of $6 \log \mathrm{CFU} \mathrm{ml}{ }^{-1}$.

\subsection{Essential oils}

Mature leaves of C. osmophloeum of six provenances were collected from the Da-Pin-Ting of Taiwan Sugar Farm (Table 1A), the Lien Hua-Chin Research Center (Table 1B-E) in Nantou County of central Taiwan and the Haw-Lin Experimental Forest (Table 1F) in Taipei County of northern Taiwan. The leaves, twigs, bark and wood of C. japonica (Table 2G-J) were obtained from 43 aged Japanese cedars grown in the Experimental Forest of National Taiwan University in Nantou County of central Taiwan. The species were identified by Mr. Yen-Ray Hsui of the Taiwan Forestry Research Institute and the voucher specimens were deposited at the Laboratory of Wood Chemistry, School of Forestry and Resource Conservation, National Taiwan University. EOs were extracted from these botanical samples ( $200 \mathrm{~g}$ each) by water distillation for $6 \mathrm{~h}$, and stored in airtight containers until analysis of oil compositions by GC-MS.

\subsection{GC-MS analysis}

The compositions of EOs from these different tissues of Japanese cedar and from $C$. osmophloeum leaf of six provenances were analyzed on a Finnigan Trace GC-Polaris Q mass instrument (Finnigan-Spectronex, Thermo, MA, USA), equipped with a fused silica column $(30 \mathrm{~m} \times 0.25 \mathrm{~mm}$ i.d.), and coated with a DB-5MS $(\mathrm{df}=0.25 \mu \mathrm{m})$. Mass spectra were recorded over the 50-650 amu range at $1 \mathrm{scans}^{-1}$, with an ionization energy of $70 \mathrm{eV}$ and an ion source temperature of 200 and $230^{\circ} \mathrm{C}$. Helium was the carrier gas at a flow rate of $1 \mathrm{ml} \mathrm{min}^{-1}$. For Japanese cedar EO, the injector temperature was maintained at $270^{\circ} \mathrm{C}$. The oven temperatures were held at $50^{\circ} \mathrm{C}$ for $2 \mathrm{~min}$, then programmed to increase from 50 to $250^{\circ} \mathrm{C}$ at a rate of $5^{\circ} \mathrm{C} \mathrm{min}-1$ and held for $5 \mathrm{~min}$. The samples $\left(1.0 \mu \mathrm{l}, 1 / 100, \mathrm{vv}^{-1}\right.$, in ethyl acetate) were injected neat with a 1:60 split ratio. C. osmophloeum leaf EOs were held at $80^{\circ} \mathrm{C}$ for $1 \mathrm{~min}$, raised to $200^{\circ} \mathrm{C}$ at a rate of $4^{\circ} \mathrm{C} \mathrm{min}{ }^{-1}$ and held for $5 \mathrm{~min}$; $250^{\circ} \mathrm{C}$ injector temperature; carrier helium at a flow rate of $1.0 \mathrm{ml} \mathrm{min}^{-1} ; 1: 10$ split ratio. Diluted samples $(1.0 \mu \mathrm{l})$ were injected manually in the split mode. Identification of individual compartments was done using the Wiley/NBS Registry of Mass Spectral Database and NIST MS Search, literature (Adams, 2001) and several authentic reference compounds. The quantity of compounds was obtained by integrating the peak area of the spectrograms.

\subsection{Antibacterial test}

Ten EOs were dissolved in $95 \%\left(\mathrm{v} \mathrm{v}^{-1}\right)$ ethanol and diluted with phosphate-buffered saline (PBS) to 200, 500, 1000 and $2000 \mu \mathrm{g} \mathrm{ml}^{-1}$. Vials containing $500 \mu \mathrm{l}$ of tested EOs were then placed in a water bath (Sheldon Manufacturing, Cornelius, OR, USA) preheated at $42^{\circ} \mathrm{C}$. Vials were inoculated with $25 \mu \mathrm{l}$ of L. pneumophila culture to give a final inoculum of $4 \log \mathrm{CFU} \mathrm{ml} \mathrm{m}^{-1}$. The negative control was prepared with $42^{\circ} \mathrm{C}$-heated PBS to which only L. pneumophila was added in the absence of EO. After 10 and $60 \mathrm{~min}$ of exposure at $42^{\circ} \mathrm{C}$ in vials with $50 \mathrm{rpm}$ shaking, $0.1 \mathrm{ml}$ of each EO sample and negative control was plated on $\mathrm{BCYE} \alpha$ agar and incubated at $37^{\circ} \mathrm{C}$ for 5 days in an atmosphere of $5 \% \mathrm{CO}_{2}$. The antibacterial 
Table 1 - Main components and their relative content (\%) of six essential oils (A-F) from C. osmophloeum leaf

\begin{tabular}{|c|c|c|c|c|c|c|c|c|c|}
\hline \multirow[t]{2}{*}{ No. } & \multirow[t]{2}{*}{ Compounds } & \multirow[t]{2}{*}{$\mathrm{RT}^{\mathrm{a}}$} & \multirow[t]{2}{*}{$\mathrm{KI}^{\mathrm{b}}$} & \multicolumn{6}{|c|}{ Relative content, \% } \\
\hline & & & & A & B & C & $\mathrm{D}$ & $E$ & $\mathrm{~F}$ \\
\hline 1 & (+)-Limonene & 5.28 & 1034 & $-^{c}$ & - & 7.31 & - & - & - \\
\hline 2 & Linalool & 6.75 & 1100 & - & - & - & 95.41 & - & 10.73 \\
\hline 3 & Camphor & 7.99 & 1151 & - & - & 53.74 & - & - & - \\
\hline 4 & Benzenepropanal & 8.34 & 1160 & 3.18 & 1.50 & - & - & - & - \\
\hline 5 & 2-Methylbenzofuran & 8.77 & 1179 & - & - & - & - & 8.27 & - \\
\hline 6 & $\alpha$-Terpineol & 9.18 & 1193 & - & - & 2.43 & 0.38 & - & 5.26 \\
\hline 7 & 4-Allylanisole & 9.36 & 1199 & 1.42 & 0.67 & - & 0.61 & 0.92 & - \\
\hline 8 & Trans-cinnamaldehyde & 11.38 & 1271 & 91.32 & 35.09 & 0.84 & 1.40 & 3.15 & 2.82 \\
\hline 9 & L-Bornyl acetate & 11.93 & 1288 & 0.59 & 0.69 & 22.09 & - & 0.94 & - \\
\hline 10 & Geranyl acetate & 14.74 & 1383 & - & - & 0.93 & - & 4.01 & 0.73 \\
\hline 11 & Cinnamyl acetate & 16.58 & 1445 & 0.44 & 56.44 & 0.58 & 1.15 & 60.77 & 0.61 \\
\hline \multirow[t]{2}{*}{12} & Spathulenol & 20.59 & 1581 & - & & - & - & 0.99 & 20.38 \\
\hline & Others & & & 3.05 & 4.51 & 12.08 & 1.05 & 17.65 & 24.77 \\
\hline Identified components, \% & & & & 100 & 98.9 & 100 & 100 & 96.7 & 65.3 \\
\hline Monterpene hydrocarbons, \% & & & & 0 & 0 & 11.1 & 0 & 0 & 0 \\
\hline Oxygenated monoterpenes, \% & & & & 0.9 & 0.7 & 80.6 & 96.2 & 5 & 26.9 \\
\hline Sesquiterpene hydrocarbons, \% & & & & 0.2 & 0.7 & 0 & 0.6 & 3.5 & 7.3 \\
\hline Oxygenated sesquiterpenes, \% & & & & 0.5 & 0.5 & 4.5 & 0 & 8.1 & 25.4 \\
\hline Other, $\%$ & & & & 98.4 & 97 & 3.8 & 3.2 & 80.1 & 5.7 \\
\hline Oil yield, \% & & & & 1.11 & 1.64 & 0.82 & 4.69 & 1.59 & 0.55 \\
\hline 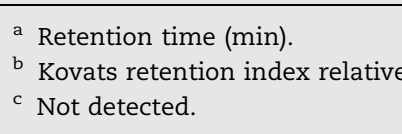 & n-alkanes $\left(C_{9}-C_{21}\right)$ on $\mathrm{DE}$ & IS colu & & & & & & & \\
\hline
\end{tabular}

Table 2 - Main components and their relative content (\%) of four essential oils (G-J) from various tissues of C. japonica

\begin{tabular}{|c|c|c|c|c|c|c|c|}
\hline \multirow[t]{2}{*}{ No. } & \multirow[t]{2}{*}{ Compounds } & \multirow[t]{2}{*}{$\mathrm{RT}^{\mathrm{a}}$} & \multirow[t]{2}{*}{$\mathrm{KI}^{\mathrm{b}}$} & \multicolumn{4}{|c|}{ Relative content, \% } \\
\hline & & & & G, bark & $\mathrm{H}$, twig & I, leaf & J, wood \\
\hline 1 & $\gamma$-Cadinene & 23.34 & 1523 & 0.66 & 2.62 & 0.06 & 22.07 \\
\hline 2 & $\delta$-Cadinene & 23.40 & 1525 & 4.65 & 10.41 & 0.55 & 12.12 \\
\hline 3 & Elemol & 24.11 & 1555 & 1.03 & 6.80 & 20.48 & 6.27 \\
\hline 4 & $\gamma$-Eudesmol & 26.00 & 1637 & 0.65 & 6.05 & 7.34 & 1.92 \\
\hline 5 & $\alpha$-Eudesmol & 26.52 & 1660 & 1.73 & 10.87 & 6.20 & 4.01 \\
\hline 6 & ent-Kaur-16-ene & 34.31 & 2044 & 2.19 & 0.11 & 20.23 & 0.09 \\
\hline 7 & Kauran-16-ol & 37.27 & 2208 & 10.22 & 3.37 & $-^{c}$ & 0.53 \\
\hline 8 & Isopimarol & 38.40 & 2302 & 4.29 & 8.98 & - & 1.77 \\
\hline \multirow[t]{2}{*}{9} & Ferruginol & 39.30 & 2334 & 14.70 & 4.68 & - & 1.52 \\
\hline & Others & & & 28.68 & 22.91 & 41.34 & 29.3 \\
\hline Identified components, \% & & & & 68.8 & 76.8 & 96.2 & 79.6 \\
\hline Monterpene hydrocarbons, \% & & & & 3.6 & - & 24.3 & - \\
\hline Oxygenated monoterpenes, \% & & & & 0.9 & - & 8.7 & - \\
\hline Sesquiterpene hydrocarbons, \% & & & & 18.4 & 22.7 & 0.8 & 48.8 \\
\hline Oxygenated sesquiterpenes, \% & & & & 11.3 & 43.3 & 40.3 & 27.5 \\
\hline Diterpene hydrocarbons, \% & & & & 8.7 & 0.6 & 22.1 & 0.3 \\
\hline Oxygenated diterpenes, \% & & & & 25.9 & 10.2 & 0.0 & 3.0 \\
\hline Oil yield, \% & & & & 0.03 & 0.05 & 1.42 & 0.38 \\
\hline 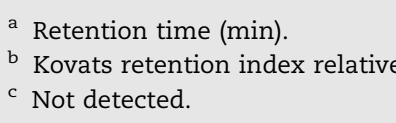 & alkanes $\left(C_{9}-C_{24}\right)$ & $5 \mathrm{MS} \mathrm{C}$ & & & & & \\
\hline
\end{tabular}

activity of EO was measured as minimal bactericidal concentrations $100\left(\mathrm{MBC}_{100}\right)$, which was defined as the concentration of the tested EO that inactivated at least $99.9 \%$
L. pneumophila and resulted in no growth of L. pneumophila on BCYE $\alpha$ agar. All of the experiments were performed in triplicate and each experiment was repeated twice. 
For positive controls, the susceptibility of L. pneumophila to erythromycin (potency $\geqq 850 \mathrm{mgg}^{-1}$, Sigma-Aldrich, St. Louis, MO, USA) and rifampicin (95\% purity, Sigma-Aldrich) was determined following the method suggested by the British Society for Antimicrobial Chemotherapy (BSAC, 2004), with modification of the use of $B C Y E \alpha$ agar instead of buffered yeast extract agar containing $5 \%$ water-lysed horse blood. The minimum inhibitory concentrations (MICs) of erythromycin and rifampicin were always observed within the ranges of 0.06-0.5 and 0.004-0.06 $\mathrm{mgl}^{-1}$, respectively, recommended for L. pneumophila (BSAC, 2004), which indicates that our test strain appropriately responded to antibacterial agents. In addition, the MICs were also found within the acceptable ranges when performing the susceptibility testing on Staphylococcus aureus ATCC 29213, a quality control strain suggested by the National Committee for Clinical Laboratory Standards (NCCLS, 1993) (data not shown).

Based on the results of the antibacterial test, four of the most effective EOs were selected to further determine their $\mathrm{MBC}$ values in response to different cell concentrations. Four to seven concentrations of EO were prepared at $100-1000 \mu \mathrm{g} \mathrm{ml}^{-1}$ in PBS. L. pneumophila cells were then adjusted to 2 and $4 \log \mathrm{CFU} \mathrm{ml} \mathrm{m}^{-1}$ in $\mathrm{PBS}$, respectively, and subjected to EO for 10 and $60 \mathrm{~min}$ at $42^{\circ} \mathrm{C}$. Plating was then performed on BCYE $\alpha$ agar and visible colonies were enumerated after incubation for 5 days. Positive and negative controls were also conducted as described previously. The percentage reduction in CFUs, defined as the inactivation rate of L. pneumophila with EO exposure, was determined as follows: $100 \times[(\mathrm{Ca}-\mathrm{Cb}) / \mathrm{Ca}]$, where $\mathrm{Ca}$ : $\mathrm{CFUs}$ of negative control at $42^{\circ} \mathrm{C}$ and $\mathrm{Cb}$ : CFUs of EO-treated sample at $42^{\circ} \mathrm{C}$. In addition to four selected EOs, the percentage reduction in CFUs was also determined for cinnamaldehyde ( $98 \%$ purity, Sigma-Aldrich) at $150-750 \mu \mathrm{g} \mathrm{ml}^{-1}$ in PBS. Cell culturability at $42{ }^{\circ} \mathrm{C}$ relative to that at room temperature in the absence of $\mathrm{EO}$ was further determined as a percentage. All of the experiments were repeated four times.

The maximum concentration of ethanol in PBS was $1 \%$ $\left(\mathrm{vv}^{-1}\right)$. Our preliminary trials revealed that the culturability of L. pneumophila in PBS containing 1\% ethanol was only reduced by $1.5 \%$ relative to that of cells in PBS without addition of ethanol (data not shown), indicating that $1 \%$ ethanol had no significant adverse effect on L. pneumophila. In addition, the beneficial effect of agar addition as an emulsifying agent in EO antibacterial activity (Burt et al., 2005) was also examined. It was observed that there was no improvement in bioactivity of EO against L. pneumophila in PBS containing 0.05\% agar. Therefore, no agar was added in the present study.

\subsection{Statistical analysis}

The inactivation rates of L. pneumophila against concentrations of EO were plotted, and the best-fit model was constructed by Sigmaplot software (SPSS Inc., Chicago, IL, USA) at $R^{2} \geqslant 0.99$. The values of $\mathrm{MBC}_{20}, \mathrm{MBC}_{50}$ and $\mathrm{MBC}_{80}$, which represented the minimum concentration of tested $\mathrm{EO}$ or the constituent that killed $20 \%, 50 \%$ and $80 \%$ of L. pneumophila, respectively, were determined from the bestfit model. In addition, the univariate analysis of variance was conducted by SPSS software (SPSS Inc.) to examine the effects of EO type, EO concentration, concentration of L. pneumophila, cell culturability and contact time on the inactivation rate of L. pneumophila. There were totally 289 samples for analysis. Pairwise comparisons between any of the two kinds of EO were further performed to examine whether the mean difference of inactivation rate was statistically significant. Forward stepwise regression analysis was also performed to determine the factors significantly affecting the inactivation of L. pneumophila for each of the EOs, and to determine the role of cinnamaldehyde using 115 inactivation data collected from cinnamaldehyde and cinnamaldehyde-containing EOs. Statistical significance was referred to as $P<0.05$ for all analyses.

\section{Results}

\subsection{Chemical compositions of EO}

As shown in Table 1, the yields of six EO (A-F) from C. osmophloeum leaf ranged between $0.55 \%$ and $4.69 \%$ (wt/dry wt). The highest oil yield was found in EO D (4.69\%), followed by EO B (1.64\%), E (1.59\%), A (1.11\%), C (0.82\%) and F (0.55\%). Totally, there were 39 compounds identified from these six leaf oils, accounting for $65.3-100 \%$ of EO. The three major components and their relative contents of each of the six EOs were trans-cinnamaldehyde (91.32\%), benzenepropanal (3.18\%) and 4-allylanisole (1.42\%) for A, cinnamyl acetate (56.44\%), trans-cinnamaldehyde (35.09\%) and benzenepropanal $(1.50 \%)$ for B, camphor (53.74\%), L-bornyl acetate $(22.09 \%)$ and $(+)$-limonene $(7.31 \%)$ for C, linalool (95.41\%), transcinnamaldehyde $(1.40 \%)$ and cinnamyl acetate $(1.15 \%)$ for D, cinnamyl acetate $(60.77 \%), 2$-methylbenzofuran $(8.27 \%)$ and geranyl acetate $(4.01 \%)$ for $E$, and spathulenol (20.38\%), linalool (10.73\%) and $\alpha$-terpineol (5.26\%) for F. Based on the identified major components and the classification by $\mathrm{Hu}$ et al. (1985), EOs A-E were classified as cinnamaldehyde type, cinnamaldehyde/cinnamyl acetate type, camphor type, linalool type and cinnamyl acetate type, respectively. However, EO $\mathrm{F}$ was classified as a mixed type due to lack of a predominant compound.

The oil yields extracted from the bark, twig, leaf and wood of C. japonica (G, H, I and J, respectively) were between $0.03 \%$ and $1.42 \%$ (Table 2). Totally, 69 compounds were identified from these four C. japonica EOs, constituting 68.8-96.2\% of EO. The three major identified components and their relative contents of G, H, I and J were, respectively, ferruginol (14.7\%), kauran-16-ol (10.22\%) and $\delta$-cadinene (4.65\%), $\alpha$-eudesmol $(10.87 \%), \delta$-cadinene $(10.41 \%)$ and isopimarol (8.98\%), elemol (20.48\%), ent-kaur-16-ene (20.23\%) and $\gamma$-eudesmol (7.34\%), and $\gamma$-cadinene $(22.07 \%), \delta$-cadinene $(12.12 \%)$ and elemol (6.27\%). Unlike C. osmophloeum leaf EO, no obviously dominant compound was identified in any of the $C$. japonica EOs.

\subsection{Anti-L. pneumophila activity of EO}

$\mathrm{MBC}_{100}$ values of EO are presented in Table 3. C. osmophloeum leaf EO possessed much stronger anti-L. pneumophila activity than C. japonica EO. In particular, four types of cinnamon leaf EOs (A-D), i.e., cinnamaldehyde type, cinnamaldehyde/ 
cinnamyl acetate type, camphor type and linalool type, demonstrated the best bactericidal properties against L. pneumophila. The culturability of L. pneumophila was completely inhibited by these four EOs at $1000 \mu \mathrm{g} \mathrm{ml}^{-1}$ for as short as a 10-min contact. Thus, these four EOs were further tested in contact with L. pneumophila at 2 and $4 \log \mathrm{CFU} \mathrm{ml} \mathrm{m}^{-1}$.

After exposure to any one of the four EOs at $750 \mu \mathrm{g} \mathrm{ml}^{-1}$ for $10 \mathrm{~min}$, the culturability of $2 \log \mathrm{CFU} \mathrm{m} \mathrm{m}^{-1}$ of L. pneumophila was inhibited completely. However, as shown in Table 4, the minimal concentration of EO to inactivate $80 \%$ L. pneumophila was found to be $436 \mu \mathrm{g} \mathrm{ml}^{-1}$ for EO A, followed by EO B $\left(523 \mu \mathrm{g} \mathrm{ml}^{-1}\right), \mathrm{C}\left(598 \mu \mathrm{g} \mathrm{ml}^{-1}\right)$ and D $\left(644 \mu \mathrm{g} \mathrm{ml}^{-1}\right)$. An increase in exposure time from 10 to $60 \mathrm{~min}$ resulted in an evident and consistent reduction of $\mathrm{MBC}_{20}, \mathrm{MBC}_{50}$ and $\mathrm{MBC}_{80}$ for each of the EOs. $\mathrm{MBC}_{100}$ of EO A was also decreased to $500 \mu \mathrm{g} \mathrm{ml}^{-1}$ at the 60-min contact, while that of the other three EOs remained at $750 \mu \mathrm{g} \mathrm{ml}^{-1}$ (data not shown). EO A was the most active $\mathrm{EO}$ as shown by the lowest $\mathrm{MBC}_{80}\left(224 \mu \mathrm{gml}^{-1}\right)$, followed by EO C $\left(245 \mu \mathrm{g} \mathrm{ml}^{-1}\right), \quad$ B $\left(451 \mu \mathrm{g} \mathrm{ml}^{-1}\right)$ and D $\left(580 \mu \mathrm{g} \mathrm{ml}^{-1}\right)$. The least effective EO against L. pneumophila was $\mathrm{EO} \mathrm{D}$, of which $\mathrm{MBC}_{20}, \mathrm{MBC}_{50}$ and $\mathrm{MBC}_{80}$ were always the highest regardless of contact time.

When cell concentration was increased to $4 \log \mathrm{CFU} \mathrm{ml}^{-1}$, at the 10-min contact, EO A still exhibited the greatest bactericidal effect, followed by EO C, D and $B$ in terms of $\mathrm{MBC}_{20}$, $\mathrm{MBC}_{50}$ and $\mathrm{MBC}_{80}$. When extending the exposure time from 10 to $60 \mathrm{~min}$, the $\mathrm{MBC}_{20}, \mathrm{MBC}_{50}$ and $\mathrm{MBC}_{80}$ of both $\mathrm{EO} A$ and $\mathrm{B}$ consistently decreased; however, this was not the case for EO $\mathrm{C}$ and D. After contacting with $4 \log \mathrm{CFU} \mathrm{m} \mathrm{l}^{-1}$ of cells for $60 \mathrm{~min}$, EO A was still the best in the aspect of Legionella inactivation with the smallest values of $\mathrm{MBC}_{20}, \mathrm{MBC}_{50}$ and $\mathrm{MBC}_{80}$. The second effective $\mathrm{EO}$ was $\mathrm{B}$, followed by $\mathrm{C}$ and $\mathrm{D}$.

Results of univariate analysis of variance showed that factors of bacterial concentration, EO type, EO concentration and exposure time had statistically significant effects on

Table $3-\mathrm{MBC}_{100}$ values of $\mathrm{C}$. osmophloeum and C. japonica essential oils against $\mathrm{L}$. pneumophila at $4 \log \mathrm{CFU} \mathrm{ml}^{-1}$ after $10-$ and 60 -min contact

\begin{tabular}{|c|c|c|}
\hline \multirow[t]{2}{*}{ Essential oils } & \multicolumn{2}{|c|}{$\mathrm{MBC}_{100}, \mu \mathrm{gml}^{-1}$} \\
\hline & $10 \mathrm{~min}$ & $60 \mathrm{~min}$ \\
\hline \multicolumn{3}{|l|}{ C. osmophloeum } \\
\hline A & 1000 & 1000 \\
\hline B & 1000 & 1000 \\
\hline $\mathrm{C}$ & 1000 & 1000 \\
\hline $\mathrm{D}$ & 1000 & 1000 \\
\hline$E$ & $>2000$ & 2000 \\
\hline $\mathrm{F}$ & $>2000$ & 2000 \\
\hline \multicolumn{3}{|l|}{ C. japonica } \\
\hline G & $>2000$ & $>2000$ \\
\hline $\mathrm{H}$ & $>2000$ & $>2000$ \\
\hline I & $>2000$ & 2000 \\
\hline$J$ & $>2000$ & $>2000$ \\
\hline \multicolumn{3}{|c|}{$\begin{array}{l}\text { Note: } \mathrm{MBC}_{100} \text { was the minimal bactericidal concentration of } \\
\text { essential oil that inactivated at least } 99.9 \% \text { of the bacteria and } \\
\text { resulted in no growth of L. pneumophila on } \mathrm{BCYE} \alpha \text { agar. The } \\
\text { essential oils were tested at } 200,500,1000 \text { and } 2000 \mu \mathrm{g} \mathrm{ml}^{-1} \text {. }\end{array}$} \\
\hline
\end{tabular}

inactivation of L. pneumophila (all P's $<0.001$ ), whereas cell culturability (determined as a percentage of the colony count at $42^{\circ} \mathrm{C}$ relative to that at room temperature) had not $(P=0.78)$. Pairwise comparison of inactivation rates demonstrated that EO A possessed inactivation ability higher than EO B, C and D (all P's <0.005), and EO B and C were also higher than EO D $(P=0.015$ and $<0.001$, respectively). No statistical difference was detected between EO B and C. The average difference of inactivation rate between EO A and EO B, C and D was $15.4 \%, 11.3 \%$ and $24.5 \%$, respectively.

The results of multiple regression models for EO A, B, C and $D$ showed that four models significantly predict the inactivation rate of $L$. pneumophila ( $P<0.001$ for all four EO models), with $R^{2}$ values ranging between 0.57 and 0.72 (Table 5). EO concentration was consistently the most significant factor positively affecting every EO's inactivation on L. pneumophila $(P<0.001$ for all four EOs). For EO A and B, the exposure time was the second significant factor $(P=0.008$ and 0.001 , respectively), whereas both cell concentration and culturability were not statistically significant. For EO C and D, however, concentration of L. pneumophila adversely affected their inactivation, shown as the second significant predictor $(P \leqslant 0.001)$. In addition to concentrations of $E O$ and L. pneumophila, inactivation ability of EO C was also significantly associated with exposure time, which was not the case in $\mathrm{EO} \mathrm{D}$.

\subsection{Anti-L. pneumophila activity of cinnamaldehyde}

According to Table 4 and results of statistical analyses, EO A and $\mathrm{B}$ exhibited the highest and moderate anti-Legionella activity, respectively. Because both EO A and B contained cinnamaldehyde accounting for $91.32 \%$ and $35.09 \%$, respectively (Table 1), we hypothesized that anti-L. pneumophila activity of these two cinnamon leaf oils could be attributed to the presence of cinnamaldehyde. Thus, we further examined the anti-L. pneumophila activity of cinnamaldehyde and compared the result with that of EO A and B. Fig. 1 shows that, at exposure for $10 \mathrm{~min}$ at $350 \mu \mathrm{g} \mathrm{ml}^{-1}$, the percentage reduction in CFUs of $L$. pneumophila caused by cinnamaldehyde was more than twice that induced by EO A, and EO B showed no CFU reduction at all. Comparable CFU reduction was found between cinnamaldehyde and EO A at 500 and $750 \mu \mathrm{g} \mathrm{ml}^{-1}$. At the 60-min contact, L. pneumophila cells were also inactivated more significantly by cinnamaldehyde than EO A at 150, 250 and $500 \mu \mathrm{g} \mathrm{ml}^{-1}$, while EO B contained the lowest antibacterial ability at all tested EO concentrations. Stepwise regression analysis of 115 inactivation data revealed that percentage of cinnamaldehyde, concentration of antibacterial agent and exposure time were significant determinants of L. pneumophila inactivation (all P's <0.001).

\section{Discussion}

The major purpose of this study was to evaluate the antibacterial properties of selected EOs against Legionella and their potential usefulness in recreational water. Previous investigation of two legionellosis outbreaks that occurred with spa and hot spring water indicates that Legionella 


\section{Table 4 - MBC values of four essential oils against L. pneumophila at two cell concentrations for 10- and 60-min contact at} $42{ }^{\circ} \mathrm{C}$

\begin{tabular}{|c|c|c|c|c|c|}
\hline \multirow[t]{2}{*}{ Cell, $\log$ CFU ml ${ }^{-1}$} & \multirow[t]{2}{*}{ Contact time, $\min$} & \multirow[t]{2}{*}{ Essential oils } & \multicolumn{3}{|c|}{$\mathrm{MBC}, \mu \mathrm{g} \mathrm{ml}^{-1}$} \\
\hline & & & $\mathrm{MBC}_{20}$ & $\mathrm{MBC}_{50}$ & $\mathrm{MBC}_{80}$ \\
\hline \multirow[t]{8}{*}{2} & 10 & A & 292 & 358 & 436 \\
\hline & & B & 454 & 486 & 523 \\
\hline & & $\mathrm{C}$ & 227 & 436 & 598 \\
\hline & & $\mathrm{D}$ & 587 & 612 & 644 \\
\hline & 60 & A & 171 & 189 & 224 \\
\hline & & B & 278 & 336 & 451 \\
\hline & & $\mathrm{C}$ & 95 & 142 & 245 \\
\hline & & $\mathrm{D}$ & 303 & 430 & 580 \\
\hline \multirow[t]{8}{*}{4} & 10 & A & 329 & 381 & 447 \\
\hline & & $\mathrm{B}$ & 555 & 636 & 716 \\
\hline & & C & 459 & 550 & 684 \\
\hline & & $\mathrm{D}$ & 498 & 577 & 688 \\
\hline & 60 & A & 158 & 208 & 311 \\
\hline & & B & 312 & 396 & 512 \\
\hline & & C & 557 & 639 & 730 \\
\hline & & $\mathrm{D}$ & 627 & 682 & 753 \\
\hline
\end{tabular}

Note: $\mathrm{MBC}_{20}, \mathrm{MBC}_{50}$ and $\mathrm{MBC}_{80}$, determined from the best-fit inactivation model against $\mathrm{EO}$ concentrations, represented the minimal concentration of EO that inactivated $20 \%, 50 \%$ and $80 \%$ of L. pneumophila, respectively. The essential oils were tested at $100-1000 \mu \mathrm{g} \mathrm{ml}^{-1}(n=4$ for each concentration).

\section{Table 5 - Multiple linear regression model of individual EO with inactivation rate as dependent variable}

\begin{tabular}{|c|c|c|c|c|c|c|c|}
\hline \multirow[t]{2}{*}{ EO } & \multirow[t]{2}{*}{ Predictors } & \multirow[t]{2}{*}{$\beta$} & \multirow[t]{2}{*}{$\mathrm{T}$} & \multirow[t]{2}{*}{$P$ value } & \multicolumn{3}{|c|}{ Model } \\
\hline & & & & & $\mathrm{F}$ & $P$ value & Adjusted $R^{2}$ \\
\hline \multirow[t]{3}{*}{ A } & & & & & 56.0 & 0.000 & 0.57 \\
\hline & EO conc. & 0.76 & 10.5 & 0.000 & & & \\
\hline & Time & 0.2 & 2.7 & 0.008 & & & \\
\hline \multirow[t]{3}{*}{ B } & & & & & 81.0 & 0.000 & 0.71 \\
\hline & EO conc. & 0.85 & 12.6 & 0.000 & & & \\
\hline & Time & 0.23 & 3.4 & 0.001 & & & \\
\hline \multirow[t]{4}{*}{ C } & & & & & 60.9 & 0.000 & 0.72 \\
\hline & EO conc. & 0.88 & 13.2 & 0.000 & & & \\
\hline & Cell conc. & -0.4 & -6.0 & 0.000 & & & \\
\hline & Time & 0.3 & 4.6 & 0.000 & & & \\
\hline \multirow[t]{3}{*}{ D } & & & & & 60.4 & 0.000 & 0.65 \\
\hline & EO conc. & 0.81 & 10.8 & 0.000 & & & \\
\hline & Cell conc. & -0.26 & -3.5 & 0.001 & & & \\
\hline
\end{tabular}

Note: The multiple linear regression model was performed with forward selection. Concentrations of EO (EO conc.) and L. pneumophila (Cell conc.), exposure time (Time) and cell culturability were initially included in the model. $\beta=$ standardized regression coefficient; $T=t$ statistic, used to evaluate the predicator; $F=F$ statistic, used to evaluate the model; adjusted $R^{2}=$ variance in inactivation rate accounted for by the predictors.

organisms reached $3-4 \log \mathrm{CFU} \mathrm{ml} \mathrm{m}^{-1}$ (NIID, 2003), while 0-3 $\log$ CFU ml ${ }^{-1}$ could be detected at no occurrence of outbreaks with L. pneumophila serogroup 1 predominating (Bornstein et al., 1989; Furuhata et al., 2004; Verissimo et al., 1991). Therefore, L. pneumophila serogroup 1 at concentrations $\leqslant 4 \log \mathrm{CFU} \mathrm{ml} \mathrm{m}^{-1}$ was examined for cellular response to the studied EOs.

Our results showed that $C$. osmophloeum leaf EO inactivated L. pneumophila better than C. japonica EO. Although the antimicrobial activity of cinnamon oil on various bacteria 
A

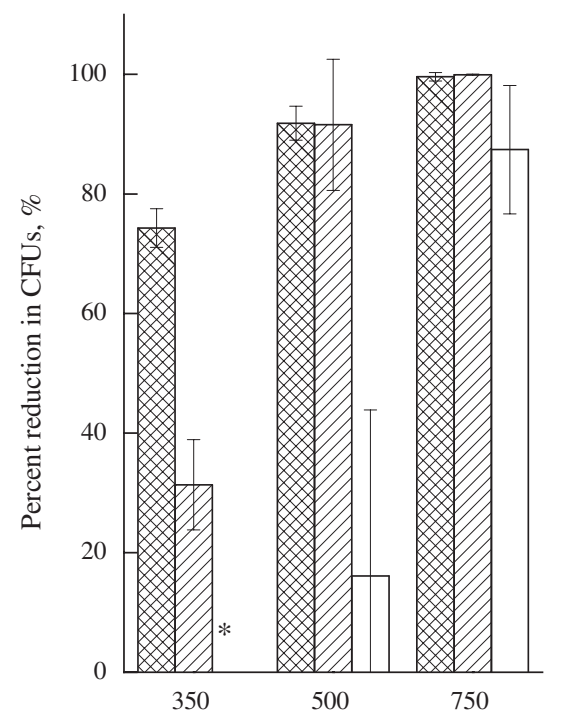

Concentration of antibacterial agent, $\mu \mathrm{g} \mathrm{ml}^{-1}$
B

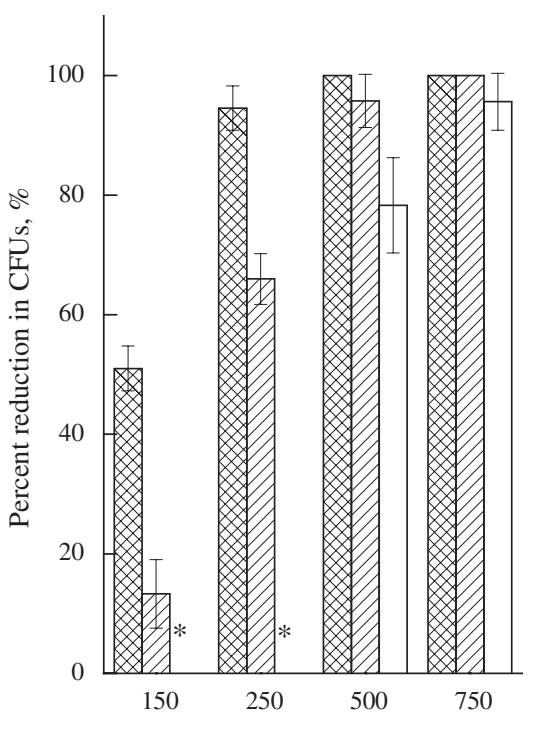

Concentration of antibacterial agent, $\mu \mathrm{g} \mathrm{ml}^{-1}$

Fig. 1 - Susceptibility of L. pneumophila of $4 \log \mathrm{CFU} \mathrm{ml}{ }^{-1}$ to antibacterial agents at $42{ }^{\circ} \mathrm{C}$ for $10-\mathrm{min}(\mathrm{A})$ and $60-\mathrm{min}$ (B) contact. The percentage reduction in CFUs, defined as the inactivation rate of L. pneumophila with exposure to antibacterial agents, is expressed as mean with an error bar representing a standard deviation. Antibacterial agents are cinnamaldehyde (m, 98\% purity), EO A (एT, cinnamaldehyde: $91.32 \%$ ) and EO B ( $\square$, cinnamaldehyde: $35.09 \%$, cinnamyl acetate: $56.44 \%)$. ${ }^{*}$ No measurable inactivation effect for EO B.

has been reported (Chang et al., 2001; Hill et al., 1997; Kim et al., 2004; Ouattara et al., 1997; Smith-Palmer et al., 1998), to the best of our knowledge, this is the first study to demonstrate the bactericidal effect of cinnamon leaf oil against Legionella species. Among the six cinnamon leaf oils studied, four EOs (i.e., A-D) had the same $M C_{100}$ of $1000 \mu \mathrm{g} \mathrm{ml}^{-1}$, which was less than that for the other two, EOs $\mathrm{E}$ and $\mathrm{F}$. This accords with our previous results that C. osmophloeum leaf EO (similar to EO A) of cinnamaldehyde type had stronger ability than that (similar to EO F) of mixed type against nine strains of bacteria (Chang et al., 2001).

The same $\mathrm{MBC}_{100}$ value found in EOs A, B, C and D (Table 3) seems to suggest that these four cinnamon leaf EOs possessed equivalent anti-L. pneumophila property. However, as we further investigated their bactericidal abilities by a number of concentrations beyond the twofold serial dilution principle and displayed the results by MBC indictors corresponding to various killing levels, we successfully distinguished their anti-L. pneumophila properties. Regardless of concentration of L. pneumophila and contact time tested, C. osmophloeum leaf EO (EO A) of cinnamaldehyde type was always the best among the four EOs, shown by its $\mathrm{MBC}_{80}$ values and by the statistical results of pairwise comparison analyses. In contrast with EO A, EO D, a linalool-type cinnamon oil, displayed the least ability against L. pneumophila with statistically significant difference. Linalool was the major component constituting up to $95.41 \%$ of EO D. Chang et al. (2001) reported that linalool showed no inhibitory effect against E. coli, P. aeruginosa, E. faecalis and $S$. aureus at $1000 \mu \mathrm{g} \mathrm{ml}^{-1}$, whereas cinnamaldehyde (the major constituent of EO A) inhibited the growth of these four bacteria at levels of $250-1000 \mu \mathrm{gml}^{-1}$. A recent study by Cheng et al.
(2006) also revealed that the antifungal activity of cinnamaldehyde-type C. osmophloeum leaf EO was higher than that of linalool-type cinnamon oil. These findings by Chang et al. and Cheng et al. on considerable difference in antimicrobial ability between linalool and cinnamaldehyde or between their respective EO imply the possibility that low antibacterial property of EO D against L. pneumophila might be attributed to its major constituent, linalool. Further studies for this possibility are warranted.

Being the most effective EO, the major constituent of EO A, cinnamaldehyde, was therefore examined for its bioactivity against L. pneumophila. The highest bactericidal effect was observed with cinnamaldehyde of $98 \%$ purity, followed by EO A containing $91.32 \%$ cinnamaldehyde and EO B with $35.09 \%$ cinnamaldehyde, indicating that the antibacterial activity was greater in the agents containing larger amounts of cinnamaldehyde. Additionally, the percentage of cinnamaldehyde in antibacterial agents was the statistically significant determinant positively affecting the inactivation rate of L. pneumophila $(P<0.001)$. On the other hand, benzenepropanal, the second highest constituent of EO A (3.18\%, Table 1), showed no antibacterial effect at $1000 \mu \mathrm{g} \mathrm{ml}^{-1}$ against $4 \log$ CFU ml ${ }^{-1}$ of L. pneumophila (data not shown). These results strongly suggest that cinnamaldehyde definitely relates to the anti-L. pneumophila property of C. osmophloeum leaf oil. Cinnamaldehyde has been identified as an effective antibacterial against a variety of foodborne pathogens (Burt, 2004; Kim et al., 2004), and its bactericidal ability was further demonstrated by the evidence of a decline in viable counts of E. coli O157:H7 with an increase in contact time and cinnamaldehyde concentration (Kim et al., 2004). We also observed a similar phenomenon when challenging 
L. pneumophila with EO A or cinnamaldehyde, indicating that both EO A and cinnamaldehyde against this particular waterborne pathogen are also bactericidal.

The antimicrobial mechanism of EO A or cinnamaldehyde on L. pneumophila is not clear. However, previous investigations on other Gram-negative bacteria have shown that cinnamaldehyde may severely damage and destroy the surface structure of E. coli 0157:H7 (Kim et al., 2004), inhibit amino acid decarboxylase activity of Enterobacter aerogenes (Wendakoon and Sakaguchi 1995) and decrease cellular glutathione levels in E. coli and S. typhimurium (Haines and Shankel 1990). The aldehyde characteristic with a conjugated double bond and a long $\mathrm{CH}$ chain outside the carbon ring is thought to contribute to the bioactivity of cinnamaldehyde primarily based on the results from cinnamaldehyde congeners (Chang et al., 2001; Wang et al., 2005). The carbonyl group of cinnamaldehyde reacting with cellular proteins by hydrogen bonding, ionic interactions and hydrophobic interactions is also suggested to be responsible for the antibacterial action (Wendakoon and Sakaguchi, 1995).

Cinnamaldehyde is recognized as a safe food additive and is widely used as a flavoring agent. It is also permitted by the US Environmental Protection Agency as the active ingredient of regulating pesticides due to the fact that cinnamaldehyde shows no unreasonable adverse effects to humans and environments and quick degradation (EPA, 2000). In particular, neither irritation nor sensitization was observed in the skin of human subjects exposed to a solution of $<3 \%$ and $<1 \%$ cinnamaldehyde, respectively (Cocchiara et al., 2005). According to Table 3, C. osmophloeum leaf EO A completely inhibited L. pneumophila at $1000 \mu \mathrm{g} \mathrm{ml}^{-1}$, which is 10 times lower than the minimum concentration (i.e., 1\%) that may cause adverse dermal effects by cinnamaldehyde. Significant anti-Legionella activity at relatively low concentrations of cinnamaldehyde indicates that $C$. osmophloeum leaf EO of cinnamaldehyde type possesses the potential to be used in recreational water against L. pneumophila, not only because of its bactericidal property but also because of its low human toxicity, quick degradation in environment and inexhaustible leaf source. In addition, the present study showed that the ability of this EO against L. pneumophila was mainly determined by EO concentration and contact time, and was not significantly affected by tested cell concentrations representing the possible levels detected during the regular period (Bornstein et al., 1989; Furuhata et al., 2004; Verissimo et al., 1991) or at LD outbreaks (NIID, 2003). The lack of a cellular concentration effect on anti-L. pneumophila properties of EO A provides another advantage in its practical application since the concentration of L. pneumophila in recreational water is usually unknown.

\section{Conclusion}

This study demonstrated that C. osmophloeum leaf oil of cinnamaldehyde type and its major constituent, cinnamaldehyde, possess remarkable anti-L. pneumophila activities, and have great potential to be used for control of Legionella growth in recreational hot water.

\section{Acknowledgments}

The authors thank Dr. Lin, Jia-Ming and Dr. Chen, Chia-Yang for their valuable comments. This study was supported by the grant from National Science Council.

R E F E R E N C E S

Adams, R.P., 2001. Identification of Essential Oil Components by Gas Chromatography/Quadrupole Mass Spectroscopy. Allured Publishing, Carol Stream, IL, USA.

Bornstein, N., Marmet, D., Surgot, M., Nowicki, M., Arslan, A., Esteve, J., Fleurette, J., 1989. Exposure to Legionellaceae at a hot spring spa: a prospective clinical and serological study. Epidemiol. Infect. 102 (1), 31-36.

BSAC, 2004. BSAC Disc Diffusion Method for Antimicrobial Susceptibility Testing. British Society for Antimicrobial Chemotherapy, Birmingham, UK.

Burt, S., 2004. Essential oils: their antibacterial properties and potential applications in food-a review. Int. J. Food Microbiol. 94 (3), 223-253.

Burt, S.A., Vlielander, R., Haagsman, H.P., Veldhuizen, E.J.A., 2005. Increase in activity of essential oil components carvacrol and thymol against Escherichia coli 0157:H7 by addition of food stabilizers. J. Food Prot. 68 (5), 919-926.

CDC, 2004. Surveillance data from public spa inspections-United States, May-September 2002. Mortal. Morbid. Weekly Rep. 53, 553-555.

Chang, C.W., Hwang, Y.H., Cheng, W.Y., Chang, C.P., 2007. Effects of chlorination and heat disinfection on long-term starved Legionella pneumophila in warm water. J. Appl. Environ. 102, 1636-1644.

Chang, S.T., Chen, P.F., Chang, S.C., 2001. Antibacterial a ctivity of leaf essential oils and their constituents from Cinnamomum osmophloeum. J. Ethnopharmacol. 77 (1), 123-127.

Chen, P.F., Chang, S.T., Wu, H.H., 2002. Antimite activity of essential oils and their components from Cinnamomum osmophloeum. Q. J. Chin. For. 35, 397-404.

Cheng, S.S., Liu, J.Y., Hsui, Y.R., Chang, S.T., 2006. Chemical polymorphism and antifungal activity of essential oils from leaves of different provenances of indigenous cinnamon (Cinnamomum osmophloeum). Bioresour. Technol. 97 (2), 306-312.

Cocchiara, J., Letizia, C.S., Lalko, J., Lapczynski, A., Api, A.M., 2005. Fragrance material review on cinnamaldehyde. Food Chem. Toxicol. 43, 867-923.

Den Boer, J.W., Yzerman, E.P., Schellekens, J., Lettinga, K.D., Boshuizen, H.C., Van Steenbergen, J.E., Bosman, A., Van den Hof, S., Van Vliet, H.A., Peeters, M.F., Van Ketel, R.J., Speelman, P., Kool, J.L., Conyn-Van Spaendonck, M.A., 2002. A large outbreak of Legionnaires' disease at a flower show, the Netherlands, 1999. Emerg. Infect. Dis. 8 (1), 37-43.

EPA, 2000. Cinnamaldehyde (040506) fact sheet. Pesticides: regulating pesticides. 〈http://www.epa.gov/pesticides/ biopesticides/ingredients/factsheets/factsheet_040506.htm $\rangle$. Environmental Protection Agency, USA.

Fields, B.S., 1997. Legionellae and Legionnaires' disease. In: Hurst, C.J., Knudsen, G.R., MeInerney, M.J., Stetzenbach, L.D., Walter, M.V. (Eds.), Manual of Environmental Microbiology. ASM Press, Washington, DC, pp. 666-675.

Fliermans, C.B., Cherry, W.B., Orrison, L.H., Smith, S.J., Tison, D.L., Pope, D.H., 1981. Ecological distribution of Legionella pneumophila. Appl. Environ. Microbiol. 41 (1), 9-16.

Friis-Moller, A., Chen, M., Fuursted, K., Christensen, S.B., Kharazmi, A., 2002. In vitro antimycobacterial and antilegio- 
nella activity of licochalcone A from Chinese licorice roots. Planta Med. 68 (5), 416-419.

Furuhata, K., Dogasaki, C., Hara, M., Fukuyama, M., 2003. Inactivation of Legionella pneumophila from whirlpool bath waters by grapefruit (Citrus paradisi) seed extract. Biocontrol Sci. 8 (3), 129-132.

Furuhata, K., Hara, M., Yoshida, S., Fukuyama, M., 2004. Distribution of Legionella spp. in hot spring baths in Japan. J. Jpn. Assoc. Infect. Dis. 78 (8), 710-716.

Greub, G., Raoult, D., 2003. Morphology of Legionella pneumophila according to their location within Hartmanella vermiformis. Res. Microbiol. 154, 619-621.

Haines, C.E., Shankel, D.M., 1990. The effects of cinnamaldehyde and vanillin in growth assays of Escherichia coli and Salmonella typhimurium. Environ. Mol. Mutagen. 15 (Suppl 17), 23-24.

Hill, P., Evans, C.S., Veness, R.G., 1997. Antimicrobial action of essential oils: the effect of dimethylsulphoxide on the activity of cinnamon oil. Lett. Appl. Microbiol. 24 (4), 269-275.

Hu, T.W., Lin, Y.T., Ho, C.K., 1985. Natural variation of chemical components of the leaf oil of Cinnamomum osmophloeum Kaneh. Bull. Taiwan For. Res. Inst. Eng. 78, 296-313 (in Chinese).

Johnson, W.M., Bernard, K., Marrie, T.J., Tyler, S.D., 1994. Discriminatory genomic fingerprinting of Legionella pneumophila by pulsed-field electrophoresis. J. Clin. Microbiol. 32 (10), 2620-2621.

Kalemba, D., Kunicka, A., 2003. Antibacterial and antifungal properties of essential oils. Curr. Med. Chem. 10 (10), 813-829.

Kim, H.O., Park, S.W., Park, H.D., 2004. Inactivation of Escherichia coli 0157:H7 by cinnamic aldehyde purified from Cinnamomum cassia shoot. Food Microbiol. 21 (1), 105-110.

Leoni, E., De Luca, G., Legnani, P.P., Sacchetti, R., Stampi, S., Zanetti, F., 2005. Legionella waterline colonization: detection of Legionella species in domestic, hotel and hospital hot water systems. J. Appl. Microbiol. 98 (2), 373-379.

Mashiba, K., Hamamoto, T., Torikai, K., 1993. A case of Legionnaires' disease due to aspiration of hot spring water and isolation of Legionella pneumophila from hot spring water. J. Jpn. Assoc. Infect. Dis. 67 (2), 163-166.

Miller, L.A., Beebe, J.L., Butler, J.C., Martin, W., Benson, R., Hoffman, R.E., Fields, B.S., 1993. Use of polymerase chain reaction in an epidemiologic investigation of Pontiac fever. J. Infect. Dis. 168 (3), 769-772.

Morita, S., Hidaka, T., Yatagai, M., 1997. Antifungal compounds of the extractives of yakusugi (Cryptomeria japonica D. Don). Wood Preserv. 23, 11-19.
Morita, Y., Matsumura, E., Okabe, T., Fukui, T., Shibata, M., Sugiura, M., Ohe, T., Tsujibo, H., Ishida, N., Inamori, Y., 2004a. Biological activity of $\alpha$-thujaplicin, the isomer of hinokitiol. Biol. Pharm. Bull. 27 (6), 899-902.

Morita, Y., Matsumura, E., Okabe, T., Fukui, T., Ohe, T., Ishida, N., Inamori, Y., 2004b. Biological activity of $\beta$-dolabrin, $\gamma$-thujaplicin, and 4-acetyltropolone, hinokitiol-related compounds. Biol. Pharm. Bull. 27 (10), 1666-1669.

NCCLS, 1993. Methods for dilution antimicrobial susceptibility tests for bacteria that grow aerobically (M7-A2). In: NCCLS Antimicrobial Susceptibility Testing. National Committee for Clinical Laboratory Standards, Pennsylvania, p. 21.

NIID, 2003. Legionellosis, April 1999-December 2002, Japan, National Institute of Infectious Diseases. Inf. Agents Surveill. Rep. 24, 27-28.

Ouattara, B., Simard, R.E., Holley, R.A., Piette, G.J.-P., Begin, A., 1997. Antibacterial activity of selected fatty acids and essential oils against six meat spoilage organisms. Int. J. Food Microbiol. 37 (2), 155-162.

Smith-Palmer, A., Steward, J., Fyfe, L., 1998. Antimicrobial properties of plant essential oils and essences against five important food-borne pathogens. Lett. Appl. Microbiol. 26 (2), 118-122.

Thomas, D.L., Mundy, L.M., Tucker, P.C., 1993. Hot tub legionellosis. Legionnaires' disease and Pontiac fever after a pointsource exposure to Legionella pneumophila. Arch. Intern. Med. 153 (22), 2597-2599.

Tolentino, A., Ahkee, S., Ramirez, J., 1996. Hot tub legionellosis. J. Ky. Med. Assoc. 94 (9), 393-394.

Verissimo, A., Marrao, G., da Silva, F.G., da Costa, M.S., 1991. Distribution of Legionella spp. in hydrothermal areas in continental Portugal and the island of Sao Miguel, Azores. Appl. Environ. Microbiol. 57 (10), 2921-2927.

Wang, S.Y., Chen, P.F., Chang, S.T., 2005. Antifungal activities of essential oils and their constituents from indigenous cinnamon (Cinnamomum osmophloeum) leaves against wood decay fungi. Bioresour. Technol. 96 (7), 813-818.

Watson, A.M., Boyce, T.G., Wylam, M.E., 2004. Legionella pneumonia: infection during immunosuppressive therapy for idiopathic pulmonary hemosiderosis. Pediatr. Infect. Dis. J. 23 (1), 82-84.

Wendakoon, C.N., Sakaguchi, M., 1995. Inhibition of amino acid decarboxylase activity of Enterobacter aerogenes by active components in spices. J. Food Prot. 58 (3), 280-283. 